\title{
Macroeconomic Adjustment in the Euro-area: The Role of Fiscal Policy
}

\author{
V. Anton Muscatelli \\ University of Glasgow and CESifo, Munich \\ Tiziano Ropele \\ Patrizio Tirelli \\ Università Milano-Bicocca Università Milano-Bicocca
}

First Draft: 15 October 2004

This Version: 22 May 2005 


\begin{abstract}
We asses the extent to which fiscal policy, as automatic stabilisers, can stabilise national economies within EMU. We use a two-country New Keynesian DGE model with liquidity constrained consumers, sticky prices, and a home bias in the composition of national consumption bundles. The model allows a variety of channels for fiscal policy, and is estimated using Euro area data. We analyse the the interaction of monetary and fiscal policies in EMU and demonstrate that, perhaps surprisingly, macroeconomic adjustment is not always facilitated by fiscal stabilisers in the case of certain types of shocks. The stabilising effects of fiscal policy at the national level are strictly dependent on the existence of home bias in consumption.
\end{abstract}

JEL Codes: E58, E62, E63 


\section{Introduction}

There is a general consensus that national fiscal policies should play an enhanced role in adjusting to macroeconomic shocks within EMU. The absence of national monetary policies, and the potentially destabilising impact of inflation differentials on real interest differentials only leave fiscal policy as a tool to offset asymmetric shocks.

Some economists have gone as far as advocating a greater emphasis on fiscal policy as a key policy instrument in macroeconomic adjustment (see Ball, 1997, Wren-Lewis, 2000, 2002). In the context of EMU, this has also led to calls to radically reform the Stability and Growth pact and render fiscal policy-making more transparent. Calmfors (2003) argues for a more transparent institutional framework for national (discretionary) fiscal policies within EMU, with clear objectives and a solution based on national fiscal committees. Other economists have challenged this perspective and see automatic stabilisers, within the constraints of a reformed SGP, as the key to macroeconomic adjustment within EMU (Buti et al., 1997, 2001, European Commission, 2001). This 'Brussels consensus' is based on the view that the ECB alone should stabilize the union-wide economy (Buti et al., 2001). The key question which we ask of this model is whether fiscal policy, through automatic stabilisers (modeled as feedback rules on output) in each country adds value to the stabilization role played by monetary policy in the Euro area.

In this this paper we examine the validity of this proposition and assess the performance of fiscal stabilisers within EMU. We do this using a small two-country model of EMU, estimated using the synthetic Euro-data collected over the period 1970-1998. While the structural model used in this paper has many elements in common with other New Keynesian dynamic stochastic general equilibrium (DSGE) models, our analysis differs in a number of respects. First, our model includes a wider range of fiscal policy transmission channels than similar New Keynesian models, including "non-Ricardian" effects on consumption due to rule-of-thumb (RT henceforth) consumers (as in Galì et al. 2002, Amato and Laubach, 2003, and Muscatelli et al. 2003b) and supply-side distortions. Second, our model is estimated, in contrast to some attempts to calibrate or numerically simulate these models (see Andres and Domenech, 2003). Third, our two-country model features a home bias in consumption which, as we shall demonstrate, impacts on how automatic fiscal stabilisers interact with monetary policy in 
a monetary union.

Earlier contributions (Andres and Domenech, 2003; Gordon and Leeper, 2003; Muscatelli et al., 2003a) found that countercyclical fiscal policy can be welfare-reducing in the presence of optimizing consumers. Muscatelli et al. (2003b) estimate the proportion of RT consumers in the US and show that automatic stabilizers based on taxation improve the performance of the economy. Here we find that the proportion of RT consumers is far larger in the Euro area, possibly due to financial market imperfections. This result is in line with a relatively large body of empirical evidence. Asdrubali and Kim (2004) find that, following an output shock, EU capital markets enable a very limited degree of consumption smoothing relative to the US. Fair (2001) finds that, unlike the US, in most EU countries there is little evidence of real interest rate effects on aggregate consumption. As we see below, this is easily reconciled with our result about the large share of RT consumers who do not directly react to interest rate shocks. Finally, our estimate is consistent with the cross country evidence about the share of current income consumers presented in Sarantis and Stewart (2003).

We use our estimates to simulate a two-country version of the model with a single central bank and independent fiscal authorities. We find that the stabilising effects of fiscal policy in response to EMU-wide shocks carry over to the case of asymmetric disturbances only if a significant home bias characterises national consumption bundles. Thus our results suggest a novel approach to the philosophy of EMU macroeconomic policymaking. At the Euro area level, the action of automatic stabilisers should be regarded as a useful complement to the ECB actions. On the other hand the usual case for fiscal stabilisation of within-EMU asymmetric shocks is confirmed only if the composition of national aggregate demand functions are sufficiently biased towards domestic production. This is in sharp contrast with the "Brussels consensus" based on the view that the ECB alone should stabilize the unionwide economy (Buti et al., 2001)

In the next section we outline our model and the empirical methodology. In Section 3, we report our econometric results and illustrate the properties of the model by looking at its impulse responses. In section 4 we consider the value added of having national fiscal stabilisers in EMU using out two country monetary union model. Section 5 concludes. 


\section{A Two-country New Keynesian Model with Home-Biased Consumer Preferences}

\subsection{General Approach}

Early vintages of New Keynesian DSGE models involved a limited role for fiscal policy, by assuming lump-sum and representative agents with infinite planning horizon. Another strand of literature has modelled more complex supply-side effects for fiscal stabilization policies by allowing taxation distortions (see Andres and Domenech, 2003 and the references therein).

Studies of the business cycle using VAR-type models do not provide empirical support for this simple description of demand-side effects in the New Keynesian model. Giavazzi et al. (2000) show that both Keynesian and neoclassical (Ricardian) effects are present. Fatas and Mihov (2001), Blanchard and Perotti (2002) and Muscatelli et al. (2004) show that fiscal shocks have conventional Keynesian effects, in that an increase in government spending causes a persistent rise in output ${ }^{1}$ and consumption. Galí et al. (2002) demonstrate that this problem can be addressed by adding non-optimising behavior to the conventional New Keynesian model. They assume that a proportion of consumers are constrained to consume out of current income and show that, under plausible parameterizations, this provides an explanation for the positive response of consumption to a temporary government spending shock. The increase in government spending generates an increase in the real wage (providing the substitution effect between consumption and leisure dominates the wealth effect), and causes an increase in aggregate consumption because 'RT' consumers spend out of current income. ${ }^{2}$ Introducing nonoptimising consumers also potentially allows for other transmission channels for fiscal policy. Even if taxes are lump sum, they will impact on aggregate consumption behaviour through their effect on the current nominal income of RT consumers. Furthermore, payroll taxes affect marginal costs and inflation. This, in turn, has an obvious impact on aggregate consumption if wages are sticky.

There are other ways, however, to model non-ricardian consumers. Debt-

\footnotetext{
${ }^{1}$ The implied fiscal multiplier is close to or greater than unity.

${ }^{2}$ Whether consumption actually increases in such models depends crucially on the assumptions made about labour supply and price-stickiness, given the linkage between consumption and leisure (and hence the real wage) via the consumer's optimization problem.
} 
financed fiscal deficits will have an impact on aggregate demand in versions of the New Keynesian model which depart from Ricardian equivalence because of the presence of finite horizons, as in the classic Blanchard-Yaari model (Leith and Wren-Lewis, 2000). Other effects of government debt on consumer behavior can also be considered, such as the impact that financial wealth has on household transactions costs, which can explain the observed positive correlation between public expenditure shocks and consumption (see Schabert, 2004).

Unfortunately there is a trade-off in estimating New Keynesian models which contain all these channels fiscal policy transmission and maintaining the model sufficiently parsimonious in terms of structural parameters to allow classical econometric techniques to be employed. A complex model will typically be underidentified with respect to the structural parameters of interest or will result in poorly-defined (in a statistical sense) estimated parameters. In modelling the transmission of fiscal policies, we have therefore chosen to restrict the demand side to the inclusion of non-optimising (RT) consumers. On the supply side, we allow for taxation effects on firms' marginal costs (through payroll taxes). This, in contrast with early attempts to estimate structural New Keynesian models ${ }^{3}$, allows for a richer range of transmission channels for fiscal policy, whilst still maintaining a model where the structural parameters are estimated using econometric methods.

\section{$2.2 \quad$ The Model}

The global economy (monetary union) consists of two countries of equal size: Home country $(\mathrm{H})$ and Foreign country $(\mathrm{F})$. We ignore third-country effects. The two economies are totally symmetric. The structural model with then reduce to a small forward-looking New Keynesian DSGE model, comprising a dynamic IS equation for output and a "New Keynesian Phillips Curve" specification for inflation for each country. In addition to the channels for fiscal policy transmission outlined above, we allow for habit formation in consumption, which is necessary to capture the observed persistence in the output-gap response to shocks.(see Leith and Malley, 2002). We model a hybrid Phillips curve, allowing for partly backward-looking inflation expectations (see Galí, Gertler and D. López-Salido, 2001, 2003).

\footnotetext{
${ }^{3}$ See Gali et al. (2001), Leith and Malley (2002), Smets and Wouters (2002).
} 


\subsubsection{Consumers}

We follow Gali et al. (2002) in assuming two types of households: those in the first group, denoted by $i$, benefit from full access to national and international capital markets and as such are free to optimize. The proportion of optimising consumers in each country is given by $(1-\vartheta)$.

The problem of the representative Home optimising consumer can be set out as follows:

$$
\max _{\left\{C_{s}^{o}, N_{s}^{o}\right\}_{s=t}^{\infty}} U_{t}^{i}=E_{t} \sum_{s=0}^{\infty} \beta^{s}\left[\frac{\left(C_{s}^{o i} / H_{s}^{i}\right)^{1-\sigma_{c}}}{1-\sigma_{c}}-\varepsilon_{s}^{n} \frac{\left(N_{s}^{o i}\right)^{1+\sigma_{n}}}{1+\sigma_{n}}\right]
$$

where $C_{t}^{o}$ represents consumption of a basket of goods (to be defined below), $H_{t}$ is an index of external habits and $N_{t}^{o}$ is the level of employment. $\beta \in(0,1)$ represents the subjective rate of time preference, $\sigma_{c}$ the coefficient of relative risk aversion, $\sigma_{n}$ the inverse of the elasticity of labour supply with respect to real wage and $\varepsilon_{s}^{n}$ is a shock to labour supply. Finally, $E_{t}$ denotes the expectation operator conditional on the time $t$ information set.

Following Smets and Wouters (2002) we assume that habits depend on past aggregate consumption, $C^{T}$ :

$$
H_{t}^{i}=\left(C_{t-1}^{T}\right)^{\lambda} .
$$

Optimizing consumers maximize (1) subject to their intertemporal budget constraint. This is expressed in real terms as:

$$
\frac{a_{t+1}^{i}}{r_{t}}=a_{t}^{i}-C_{t}^{o i}+\frac{W_{t}}{P_{t}} N_{t}^{o i}+D_{t}^{i}-T_{t}^{i}
$$

Their financial wealth $\left(a_{t}\right)$ is held in the form of one-period state-contingent securities, which yield a return of $r_{t}$. Home households can hold their wealth in bonds issued in country $\mathrm{H}, B_{H, t}$, and bonds issued in country $\mathrm{F}, B_{F}$, which offer the same return $\left(a_{t}=B_{H, t}+B_{F, t}\right)$. The optimizing consumer's disposable income is defined as consisting of labour income $w_{t} N_{t}^{o i}$ plus the dividends from the profits of the imperfectly competitive firms $D_{t}^{i}$, minus personal taxes $T_{t}^{i}$, which are lump-sum by assumption.

The second group of households, a proportion $\vartheta$ of the total, follows a rule of thumb behaviour: these households consume out of current disposable 
income, and supply a constant amount of labour $4, \overline{N^{R T}}$. This admittedly ad hoc assumption may be justified assuming myopia or limited participation to capital markets. Thus, the consumption function of the representative rule-of-thumb consumer is:

$$
C_{t}^{R T j}=\bar{N}^{R T} \frac{W_{t}}{P_{t}}-T_{t}^{j}
$$

The Home Country Household's Optimisation Problem Rearranging the first order conditions associated with (1) and aggregating across consumers over $i \in\left(\frac{\vartheta}{2}, \frac{1}{2}\right]$ yields the consumption intertemporal Euler equation:

$$
\frac{\left(C_{t}^{o} / C_{t-1}^{\lambda}\right)^{-\sigma_{c}}}{C_{t-1}^{\lambda}}=E_{t}\left\{\beta \frac{\left(C_{t+1}^{o} / C_{t}^{\lambda}\right)^{-\sigma_{c}}}{C_{t}^{\lambda}} R_{t} \frac{P_{t}}{P_{t+1}}\right\}
$$

RT consumers residing in country $H$, consume according to their current disposable income:

$$
C_{t}^{R T}=\bar{N}^{R T} \frac{W_{t}}{P_{t}}-T_{t}
$$

Given the symmetry of the model, equations (5) and (6) hold true also for country $\mathrm{F}$ :

$$
\frac{\left(C_{t}^{* o} / C_{t-1}^{* \lambda}\right)^{-\sigma_{c}}}{C_{t-1}^{* \lambda}}=E_{t}\left\{\beta \frac{\left(C_{t+1}^{* o} / C_{t}^{* \lambda}\right)^{-\sigma_{c}}}{C_{t}^{* \lambda}} R_{t}^{*} \frac{P_{t}^{*}}{P_{t+1}^{*}}\right\}
$$

and

$$
C_{t}^{* R T}=\bar{N}^{* R T} \frac{W_{t}^{*}}{P_{t}^{*}}-T_{t}^{*}
$$

where $C_{t}^{* o} \equiv \int_{(1+\vartheta) / 2}^{1} C_{t}^{* o i} d i$ and $C_{t}^{* R T} \equiv \int_{1 / 2}^{(1+\vartheta) / 2} C_{t}^{* R T i} d i$.

At a given time $t$ each household is called to solve an intratemporal problem for the optimal choice of consumption bundles (defined below) and differentiated consumption goods, indexed by $z \in[0,1]$. We let goods whose index

\footnotetext{
${ }^{4}$ Galì et al. (2002) show that supplying a constant amount of labour is optimal when personal taxes, $T_{t}$, levied on rule-of-thumb consumers are always nil. This result would never obtain in our model, where taxes and transfers are explicitly modeled. Thus, for sake of simplicity we assume a constant labour supply. Since consumption cannot be negative, this implies that we impose a lower bound on $T_{t}$ for any given level of the real wage.
} 
$z \in\left[0, \frac{1}{2}\right]$ to be produced in country $\mathrm{H}$ whereas the remaining in country $\mathrm{F}^{5}$ Preferences over consumption bundles are modelled according to a constant elasticity of substitution (CES) specification with paramter $0.5<\chi<1$ capturing idiosyncratic taste or home bias:

$$
C_{t}=\left[\chi^{\frac{1}{\eta}} C_{H, t}^{\frac{\eta-1}{\eta}}+(1-\chi)^{\frac{1}{\eta}} C_{F, t}^{\frac{\eta-1}{\eta}}\right]^{\frac{\eta}{\eta-1}}
$$

Subindeces $C_{H, t}$ and $C_{F, t}$ are themselves constructed as CES aggregators, i.e:

$$
C_{H, t}=\left[\int_{0}^{\frac{1}{2}} C_{H, t}(z)^{\frac{\theta-1}{\theta}} d z\right]^{\frac{\theta}{\theta-1}} \text { and } C_{F, t}=\left[\int_{\frac{1}{2}}^{1} C_{F, t}(z)^{\frac{\theta-1}{\theta}} d z\right]^{\frac{\theta}{\theta-1}} .
$$

Parameters $\eta$ and $\theta$, both assumed greated than one, respectively measure the elasticity of substitution between consumption bundles $C_{H, t}$ and $C_{F, t}$ and the elasticity of substitution among each of the differentiated goods either being produced in country $\mathrm{H}$ or $\mathrm{F}$.

Solving the cost minimization problem for the purchase of one unit of the composite consumption $C_{t}$ gives rise the Home household's demand schedules for $C_{H, t}$ and $C_{F, t}$ :

$$
C_{H, t}=\chi\left(\frac{p_{H, t}}{P_{t}}\right)^{-\eta} C_{t} \text { and } C_{F, t}=(1-\chi)\left(\frac{p_{F, t}}{P_{t}}\right)^{-\eta} C_{t}
$$

In the same vein, Home household's demand schedules for good $z$ produced in country $\mathrm{H}$ and $\mathrm{F}$ are given by:

$$
c_{H, t}(z)=\left(\frac{p_{H, t}(z)}{P_{H, t}}\right)^{-\theta} C_{H, t} \text { and } c_{F, t}(z)=\left(\frac{p_{F, t}(z)}{P_{F, t}}\right)^{-\theta} C_{F, t}
$$

Two things are noteworthy. First, demand functions for consumption bundles $C_{H, t}$ and $C_{F, t}$ are affected by the home bias parameter $\chi$ : even in the instance of $p_{H, t}=p_{F, t}$ the ratio of $\mathrm{H}$-produced goods to F-produced goods is higher in the Home country. Second, in the case $\eta=\theta$, demand functions for $c_{H, t}(z)$ and $c_{F, t}(z)$ reduce to:

$$
c_{H, t}(z)=\chi\left(\frac{p_{H, t}(z)}{P_{t}}\right)^{-\theta} C_{t} \text { and } c_{F, t}(z)=(1-\chi)\left(\frac{p_{F, t}(z)}{P_{t}}\right)^{-\theta} C_{t}
$$

\footnotetext{
${ }^{5}$ In what follows subscript $\mathrm{H}$ or $\mathrm{F}$ denote the country where differentiated consumption goods are produced.
} 
In the rest of the analysis we continue to assume that $\eta=\theta$.

By symmetry, in country $\mathrm{F}$ the following relations hold true:

$$
\begin{aligned}
C_{t}^{*} & =\left[(1-\chi)^{\frac{1}{\eta}} C_{H, t}^{* \frac{\eta-1}{\eta}}+\chi^{\frac{1}{\eta}} C_{F, t}^{* \frac{\eta-1}{\eta}}\right]^{\frac{\eta}{\eta-1}} \\
C_{H, t}^{*} & =\left[\int_{0}^{\frac{1}{2}} C_{H, t}^{*}(z)^{\frac{\theta-1}{\theta}} d z\right]^{\frac{\theta}{\theta-1}} \text { and } C_{F, t}^{*}=\left[\int_{\frac{1}{2}}^{1} C_{F, t}^{*}(z)^{\frac{\theta-1}{\theta}} d z\right]^{\frac{\theta}{\theta-1}} \\
C_{H, t}^{*} & =(1-\chi)\left(\frac{p_{H, t}^{*}}{P_{t}^{*}}\right)^{-\eta} C_{t}^{*} \text { and } C_{F, t}^{*}=\chi\left(\frac{p_{F, t}^{*}}{P_{t}^{*}}\right)^{-\eta} C_{t}^{*} \\
c_{H, t}^{*}(z) & =(1-\chi)\left(\frac{p_{H, t}^{*}(z)}{P_{t}^{*}}\right)^{-\theta} C_{t}^{*} \text { and } c_{F, t}^{*}(z)=\chi\left(\frac{p_{F, t}^{*}(z)}{P_{t}^{*}}\right)^{-\theta} C_{t}^{*}
\end{aligned}
$$

Consumption-Based Price Indices The consumption price index which minimizes the cost of purchasing one unit of $C_{t}$ and $C_{t}^{*}$ reads as:

$$
\begin{aligned}
P_{t} & =\left[\chi P_{H, t}^{1-\eta}+(1-\chi) P_{F, t}^{1-\eta}\right]^{\frac{1}{1-\eta}} \\
P_{t}^{*} & =\left[\chi P_{F, t}^{1-\eta}+(1-\chi) P_{H, t}^{1-\eta}\right]^{\frac{1}{1-\eta}}
\end{aligned}
$$

where, in turn, $P_{H, t}$ and $P_{F, t}$ are given by:

$$
P_{H, t}=\left[\int_{0}^{1 / 2} p_{H, t}(z)^{1-\theta} d z\right]^{\frac{1}{1-\theta}} \text { and } P_{F, t}=\left[\int_{1 / 2}^{1} p_{F, t}(z)^{1-\theta} d z\right]^{\frac{1}{1-\theta}} \text {. }
$$

Because there are no impediments to trade and the two countries share the same currency the price of each differntiated good is the same in both countries:

$$
\begin{aligned}
p_{H, t}(z) & =p_{H, t}^{*}(z) \\
p_{F, t}(z) & =p_{F, t}^{*}(z)
\end{aligned}
$$

Thus, it also follows that $P_{H, t}^{*}=P_{H, t}$ and $P_{F, t}^{*}=P_{F, t}$. However, due to the idiosyncratic taste introduced in the preferences over consumption bundles, purchasing power parity does not hold in general. Hence:

$$
P_{t} \neq P_{t}^{*} \text {. }
$$




\subsubsection{Firms}

In each economy there is a continuum of firms, producing the varieties of goods, and they act as monopolistic competitors. We assume a fixed capital stock, and firms' output of each good variety $z$ follows a Cobb-Douglas technology which depends on employment, $N$ and a technology parameter $A_{t}$ :

$$
Y_{t}(z)=A_{t}\left[N_{t}(z)\right]^{1-\alpha}
$$

We introduce a channel for fiscal policy by assuming that taxes on labour take the form of a uniform payroll tax ${ }^{6}$. Firms' demand for labour in each country for for each good variety is therefore defined as:

$$
p_{j, t}(z)\left\{(1-\alpha) A_{t}\left[N_{t}(z)\right]^{-\alpha}-t_{t}^{P R}\right\}=W_{t} \quad j=F, H
$$

where $t_{t}^{P R}$ is the tax rate per unit of employed labour, i.e. $t_{t}^{P R}=\frac{T_{t}^{P R}}{N_{t}}$, where $T_{t}^{P R}$ are the total revenues from the payroll tax.

We turn next to firms' pricing behavior. We consider a standard model of monopolistic competition with sticky prices, as set out in Galí, Gertler and López-Salido (2001), and Leith and Malley (2002) . More precisely, sticky prices are incorporated into this model by assuming a Calvo pricing mechanism, whereby only a given proportion of firms, defined as $(1-\xi)$, can adjust prices every period whereas the remainder supplies output on demand at a constant price. A share $\gamma$ of the adjusting firms is assumed to index prices to inflation in the previous period ${ }^{8}$, while the remaininder, $(1-\gamma)$, set their prices optimally to maximize expected discounted real profits ${ }^{9}$, with a discount factor $\beta$.

\subsubsection{Fiscal Authority}

In modelling the fiscal authorities' behaviour in each country therer are two possible alternatives. On the one hand, we can consider fiscal authorities

\footnotetext{
${ }^{6}$ This implies that the optimizing consumer's choice between leisure and consumption is not affected.

${ }^{7}$ See also Erceg, Henderson and Levin (2000), and Sbordone (2002).

${ }^{8}$ This was pioneered by Galí and Gertler (1999). Similar backward-looking elements can be introduced to the NKPC equation by introducing indexation of all non-re-optimised prices (Christiano, Eichenbaum and Evans, 2001, and Woodford, 2002, chapter 3).

${ }^{9}$ A similar specification for the New Keynesian Phillips curve can be obtained by making the indexation process part of the optimisation process (see Smets and Wouters, 2002).
} 
as having the same households' preferences (with the bias parameter as well). In this case, total demand for the generic good $z$ stems from domestic and foreign households' consumption and from domestic and foreign governments'consumption. In this case:

$$
g_{H, t}(z)=\chi\left(\frac{p_{H, t}(z)}{p_{H, t}}\right)^{-\theta}\left(\frac{p_{H, t}}{P_{t}}\right)^{-\eta} G_{t}
$$

On the other hand, we can model domestic fiscal authority's preferences as defined only on domestically-produced goods and similarly for the foreign fiscal authority. In this case:

$$
g_{H, t}(z)=\left(\frac{p_{H, t}(z)}{P_{H, t}}\right)^{-\theta} G_{t}
$$

For sake of simplicity we shall model public expenditures according to the latter specification.

\subsubsection{The Global Economy}

The solution method first requires to derive expressions for the world weighted averages: $X_{t}^{W}=\frac{1}{2}\left[X_{t}+X_{t}^{*}\right]$. Country specific variable are thus given by: $X_{t}=X_{t}^{W}+\frac{1}{2}\left[X_{t}-X_{t}^{*}\right]$.

Let us define two others variables that we will be useful throughout the analysis. The CPI-based real exchange rate

$$
Q_{t}=\frac{P_{t}^{*}}{P_{t}}
$$

and the terms of trade:

$$
S_{t}=\frac{P_{F, t}}{P_{H, t}}
$$

At world economy level the resource constraint implies that:

$$
\begin{aligned}
Y_{t}^{W} & =C_{t}^{W}+G_{t}^{W} \\
Y_{t}+Y_{t}^{*} & =C_{t}+C_{t}^{*}+G_{t}+G_{t}^{*}
\end{aligned}
$$

where according to our notation: $Y_{t}^{W}=\frac{1}{2}\left[Y_{t}+Y_{t}^{*}\right], G_{t}^{W}=\frac{1}{2}\left[G_{t}+G_{t}^{*}\right]$. 


\subsubsection{Log-linearization}

Equation (10) and (11) become:

$$
\begin{aligned}
& \hat{P}_{t}=\chi \hat{P}_{H, t}+(1-\chi) \hat{P}_{F, t} \\
& \hat{P}_{t}^{*}=(1-\chi) \hat{P}_{H, t}^{*}+\chi \hat{P}_{F, t}^{*}
\end{aligned}
$$

where in what follows, hatted variables denote log-deviations from the steady state and barred variables denote steady-state values.

The log-linearized real exchange rate and the terms of trade read as:

$$
\hat{Q}_{t}=\hat{P}_{t}^{*}-\hat{P}_{t} \text { and } \hat{S}_{t}=\hat{P}_{F, t}-\hat{P}_{H, t} .
$$

\subsubsection{World demand schedules for Home and Foreign differenti- ated good}

World demand schedules for the generic $z$ Home produced differentiated good is given by:

$$
\begin{aligned}
y_{t}(z) & =c_{H, t}(z)+c_{H, t}^{*}(z)+g_{H, t}(z)+g_{H, t}^{*}(z) \\
& =\chi\left(\frac{p_{H, t}(z)}{P_{H, t}}\right)^{-\theta}\left(\frac{P_{H, t}}{P_{t}}\right)^{-\eta}\left[C_{t}+G_{t}\right]+(1-\chi)\left(\frac{p_{H, t}^{*}(z)}{p_{H, t}^{*}}\right)^{-\theta}\left(\frac{P_{H, t}^{*}}{P_{t}^{*}}\right)^{-\eta}\left[C_{t}^{*}+G_{t}^{*}\right]
\end{aligned}
$$

Integrating over $z \in[0,1 / 2]$ leads to:

$$
Y_{t}=\int_{0}^{1 / 2} y_{t}(z) d z=\chi \tilde{D}_{H, t}\left(\frac{P_{H, t}}{P_{t}}\right)^{-\eta}\left[C_{t}+G_{t}\right]+(1-\chi) \tilde{D}_{H, t}\left(\frac{p_{H, t}^{*}}{P_{t}^{*}}\right)^{-\eta}\left[C_{t}^{*}+G_{t}^{*}\right]
$$

where $\tilde{D}_{H, t}=\int_{0}^{1 / 2}\left(\frac{p_{H, t}(z)}{P_{H, t}}\right)^{-\theta} d z=\int_{0}^{1 / 2}\left(\frac{p_{H, t}^{*}(z)}{p_{H, t}^{*}}\right)^{-\theta} d z$.

Evaluating the above expression in steady state and normalising prices to one (i.e. $p_{H}=P=P^{*}=1$ ) yields to:

$$
Y=\chi[C+G]+(1-\chi)\left[C^{*}+G^{*}\right]
$$

Loglinearisation of (14) around the deterministic zero inflation steady state leads to: 


$$
\begin{aligned}
\hat{Y}_{t}= & \chi \eta\left[\frac{\bar{C}+\bar{G}}{\bar{Y}}\right]\left(\hat{P}_{t}-\hat{P}_{H, t}\right)+\chi\left(\frac{\bar{C}}{\bar{Y}}\right) \hat{C}_{t}+\frac{\bar{G}}{\bar{Y}} \hat{G}_{t} \\
& +(1-\chi) \eta\left[\frac{\overline{C^{*}}+\overline{G^{*}}}{\bar{Y}}\right]\left(\hat{P}_{t}^{*}-\hat{P}_{H, t}\right)+(1-\chi)\left(\frac{\overline{C^{*}}}{\bar{Y}}\right) \hat{C}_{t}^{*}
\end{aligned}
$$

The quantities $\left(\hat{P}_{t}-\hat{P}_{H, t}\right)$ and $\left(\hat{P}_{t}^{*}-\hat{P}_{H, t}\right)$ can equivalently be rewritten in terms of $\hat{S}_{t}$ as:

$$
\begin{gathered}
\hat{P}_{t}-\hat{P}_{H, t}=(1-\chi) \hat{S}_{t} \\
\hat{P}_{t}^{*}-\hat{P}_{H, t}=\chi \hat{S}_{t}
\end{gathered}
$$

Therefore:

$$
\hat{Y}_{t}=\Gamma \hat{S}_{t}+\chi\left(\frac{\bar{C}}{\bar{Y}}\right) \hat{C}_{t}+\frac{\bar{G}}{\bar{Y}} \hat{G}_{t}+(1-\chi)\left(\frac{\overline{C^{*}}}{\bar{Y}}\right) \hat{C}_{t}^{*}+\frac{\overline{G^{*}}}{\bar{Y}} \hat{G}_{t}^{*}
$$

where $\Gamma=\left\{\frac{\bar{C}+\bar{G}+\overline{C^{*}}+\overline{G^{*}}}{\bar{Y}}\right\} \chi(1-\chi) \eta$.

\subsection{Deriving the IS and the Phillips Curves}

\subsubsection{The IS Curve}

In country $\mathrm{H}$ :

$$
\hat{C}_{t}=\left[\overline{\frac{C^{o}}{\bar{C}}}\right] \hat{C}_{t}^{o}+\left[\overline{\frac{C^{R T}}{\bar{C}}}\right] \hat{C}_{t}^{R T}
$$

and in addition:

$$
\begin{aligned}
& \hat{c}_{t}^{R T}=\frac{\overline{N^{R T}}\left(\overline{\frac{W}{P}}\right)}{\overline{C^{R T}}}\left(w_{t}-\hat{p}_{t}\right)-\vartheta\left(\frac{\bar{T}}{\overline{C^{R T}}}\right) \hat{T}_{t} \\
& \hat{C}_{t}^{o}=\hat{C}_{t+1}^{o}-\lambda\left(\frac{1-\rho}{\rho}\right)\left[\hat{C}_{t-1}-\hat{C}_{t}\right]-\frac{1}{\rho} r_{t}
\end{aligned}
$$

Analogously, in country $\mathrm{F}$ we have the following expressions:

$$
\hat{C}_{t}^{*}=\left[\overline{\overline{C^{o *}}} \overline{\overline{C^{*}}}\right] \hat{C}_{t}^{o *}+\left[\overline{\frac{C^{R T *}}{\overline{C^{*}}}}\right] \hat{C}_{t}^{R T *}
$$




$$
\begin{gathered}
\hat{C}_{t}^{R T *}=\frac{\overline{N^{R T *}}\left(\overline{\frac{W^{*}}{P^{*}}}\right)}{\overline{C^{R T *}}}\left(w_{t}^{*}-\hat{p}_{t}^{*}\right)-\vartheta\left(\frac{\overline{T^{*}}}{\overline{C^{R T *}}}\right)\left(\hat{T}_{t}^{*}\right) \\
\hat{C}_{t}^{o *}=\hat{C}_{t+1}^{o *}-\lambda\left(\frac{1-\rho}{\rho}\right)\left[\hat{C}_{t-1}^{*}-\hat{C}_{t}^{*}\right]-\frac{1}{\rho} r_{t}
\end{gathered}
$$

Note that if we imposed no habit, $\lambda=0$, and had no RT consumers, $\frac{\overline{N^{R T}}}{\bar{N}}=\vartheta=0$, our specification for the model would collapse to a purely forward looking IS curve (see Carroll, 2000). Moreover, the presence of nonoptimizing consumers establishes a link between the demand for goods, net personal taxes, $\widehat{T}$, and the real wage.

After lengthy but straightforward manipulations we get the two IS equations

$$
\begin{aligned}
\Delta \hat{Y}_{t+1}= & \kappa_{1}\left(i_{t}-\pi_{t+1}\right)+\kappa_{2} \Delta \hat{S}_{t+1}-\kappa_{3} \Delta \hat{S}_{t}+k_{4} \Delta \hat{C}_{t}^{R T}+\kappa_{5} \Delta \hat{G}_{t+1}+(17) \\
& +k_{6} \Delta \hat{Y}_{t+1}^{*}-k_{7} \Delta \hat{G}_{t+1}^{*}+\kappa_{8} \Delta \hat{Y}_{t}+ \\
& -\kappa_{9} \Delta \hat{Y}_{t}^{*}-\kappa_{10} \Delta \hat{G}_{t}+\kappa_{11} \Delta \hat{G}_{t}^{*} \\
\Delta \hat{Y}_{t+1}^{*}= & \kappa_{1}\left(i_{t}-\pi_{t+1}^{*}\right)-\kappa_{2} \Delta \hat{S}_{t+1}+\kappa_{3} \Delta \hat{S}_{t}+k_{4} \Delta \hat{C}_{t}^{R T *}+\kappa_{5} \Delta \hat{G}_{t+1}^{*}(18) \\
& +k_{6} \Delta \hat{Y}_{t+1}-k_{7} \Delta \hat{G}_{t+1}+\kappa_{8} \Delta \hat{Y}_{t}^{*}+ \\
& -\kappa_{9} \Delta \hat{Y}_{t}-\kappa_{10} \Delta \hat{G}_{t}^{*}+\kappa_{11} \Delta \hat{G}_{t} \\
&
\end{aligned}
$$


where

$$
\begin{array}{ll}
\kappa_{1}=\frac{\overline{C^{O}}}{\bar{C}}\left(\frac{1}{\rho}\right)\left(\frac{2 \chi-1}{\chi}\right) & k_{7}=\left(\frac{1-\chi}{\chi}\right) \frac{\bar{G}}{\bar{Y}} \\
\kappa_{2}=\frac{\Gamma}{\chi}=\frac{\left(\frac{\bar{C}+\bar{G}+\overline{C^{*}}+\overline{G^{*}}}{\bar{\chi}}\right)}{\chi} & \kappa_{8}=\left[\lambda \overline{\frac{C^{O}}{\bar{C}}}\left(\frac{\rho-1}{\rho}\right)\right] \frac{1}{\chi} \\
\kappa_{3}=\left[\lambda \frac{\overline{C^{O}}}{\bar{C}}\left(\frac{\rho-1}{\rho}\right)\right] \frac{1}{\chi^{2}} & \kappa_{9}=\left[\lambda \overline{C^{O}}\left(\frac{\rho-1}{\rho}\right)\right] \frac{1-\chi}{\chi^{2}} \\
k_{4}=\left(\frac{2 \chi-1}{\chi}\right) & \kappa_{10}=\left[\lambda \frac{\overline{C^{O}}}{\bar{C}}\left(\frac{\rho-1}{\rho}\right)\right] \frac{1}{\chi} \frac{\bar{G}}{\bar{Y}} \\
k_{5}=\frac{\bar{G}}{\bar{Y}} & \kappa_{11}=\left[\lambda \overline{\frac{C^{O}}{\bar{C}}}\left(\frac{\rho-1}{\rho}\right)\right] \frac{1-\chi}{\chi^{2}} \frac{\bar{G}}{\bar{Y}} \\
k_{6}=\left(\frac{1-\chi}{\chi}\right) &
\end{array}
$$

and

$$
\begin{gathered}
\widehat{\pi}_{t}=\chi \widehat{\pi}_{H, t}+(1-\chi) \widehat{\pi}_{F, t} \\
\widehat{\pi}^{*}{ }_{t}=(1-\chi) \widehat{\pi}_{F, t}+\chi \widehat{\pi}_{H, t} \\
\Delta \hat{S}_{t}=\widehat{\pi}_{F, t}-\widehat{\pi}_{H, t}
\end{gathered}
$$

$\widehat{\pi}_{t}, \widehat{\pi}^{*}{ }_{t}$ respectively define domestic and foreign consumer price inflation rates in terms of the inflation rates of domestically and foreign produced goods.

Fiscal policy directly impacts on output in this model through three channels. First, through the usual resource withdrawal effect of government consumption, $\widehat{g}_{t}$. Second, through the impact of net personal taxes $\widehat{T}$ on the current disposable income of rule-of-thumb consumers. Third, through the impact of payroll taxes $T^{P R}$ on the real wage of rule-of-thumb consumers ${ }^{10}$. Finally, rule-of-thumb consumers weaken the impact of interest rate policy on aggregate demand. As shown in Galì et al. (2002) this may have important implications for the conduct of monetary policy. Indeed, our estimates

\footnotetext{
${ }^{10}$ From equations (4) and (13) it should be clear that, in each period, the equilibrium real wage is inversely related to employment and the payroll tax. As we show in the Appendix, it is the rate of change of these variables that affects current output.
} 
confirm that rule-of-thumb consumers weaken the output response to interest rate changes.

It is important to note that whilst government spending impacts on the consumption behaviour of optimising consumers via the resource-withdrawal effect, taxation impacts through its effect on disposable income for ruleof-thumb consumers, and hence via the external habit (total consumption) variable. This ensures that government spending enters via a distributed lag in $(17,18)$, while personal and payroll taxes enter in differences, with coefficients of different size. As we shall see below, this drives some of the results of the model.

\subsubsection{The Phillips Curve}

The log-linearization of the firms' optimal pricing decision together with the dynamic equation for the price index under the Calvo mechanism with indexation, leads to a New Keynesian Phillips Curve (NKPC): (see Gali et al., 2001, 2003, Muscatelli et al., 2003b) for details). For each country, the Phillips curves are defined for the bundle of domestically produced goods:

$$
\begin{aligned}
& \widehat{\pi}_{H, t}=\frac{\gamma \widehat{\pi}_{H, t-1}+\beta \xi E_{t} \widehat{\pi}_{H, t+1}}{\xi+\gamma(1-\xi(1-\beta))}+\frac{(1-\gamma)(1-\xi)(1-\gamma \xi)}{[\xi+\gamma(1-\xi(1-\beta))][1+(\alpha /(1-\alpha)) \theta]} \widehat{s}_{H, t} \\
& \widehat{\pi}_{F, t}=\frac{\gamma \widehat{\pi}_{F, t-1}+\beta \xi E_{t} \widehat{\pi}_{F, t+1}}{\xi+\gamma(1-\xi(1-\beta))}+\frac{(1-\gamma)(1-\xi)(1-\gamma \xi)}{[\xi+\gamma(1-\xi(1-\beta))][1+(\alpha /(1-\alpha)) \theta]} \widehat{s}_{F, t} \\
& \widehat{s}_{H, t}=\overline{\frac{N\left(\frac{W}{P}\right)}{\overline{N\left(\frac{W}{P}\right)}+\overline{T^{*}}}}\left(\widehat{w_{H, t}}-\widehat{p_{H, t}}\right)+\frac{\overline{T^{*}}}{\overline{N\left(\frac{W}{P}\right)}+\overline{T^{*}}}\left(\widehat{t_{H, t}^{*}}-\widehat{n_{H, t}}\right)+\widehat{n_{H, t}}-\widehat{y_{H, t}} \\
& \widehat{s}_{F, t}=\overline{\frac{N\left(\frac{W}{P}\right)}{\overline{N\left(\frac{W}{P}\right)}+\overline{T^{*}}}}\left(\widehat{w_{F, t}}-\widehat{p_{F, t}}\right)+\frac{\overline{T^{*}}}{\overline{N\left(\frac{W}{P}\right)}+\overline{T^{*}}}\left(\widehat{t_{F, t}^{*}}-\widehat{n_{F, t}}\right)+\widehat{n_{F, t}}-\widehat{y_{F, t}}
\end{aligned}
$$


where $\widehat{s}_{i, t}$ is the percentage deviation from steady state of the labour cost share $^{11}$

It is important to note that in estimating the parameters of the Phillips Curves, we do not explicitly model wage-setting behaviour, and the determination of employment is given by the static production function. Other recent contributions (Leith and Malley, 2002, Smets and Wouters, 2002) estimate wage equations, and adding a wage equation would have enabled us to consider the possibility of sticky wage dynamics with some forward-lookingness in wage-setting. However, this would have also added to the complexity of the model. In simulating our model, as we shall see below, we introduce an element of adjustment in nominal wages. This amplifies the inertia generated by RT consumers as the flexible wage introduces an immediate change in RT consumption.

\section{Empirical Estimates}

\subsection{Data}

In order to simulate our model, we need to estimate or calibrate the parameter values. As we intend to employ a symmetric model of the EMU area, the best approach is to estimate the values of the parameters using aggregate Euro-area data, and by assumption use these parameters for our two repersentative countries ( $\mathrm{H}$ and $\mathrm{F}$ ).

The data employed is the aggregated Euro-area data produced by the European Central Bank (see Fagan, Henry and Mestre, 2001). The time series are quarterly over the sample period 1970(1)-1998(2). While we obtain new estimates of the structural parameters present for the global IS curve, for the NKPC we essentially use the estimates reported in Galí et al. (2001, 2003), as these were obtained using the same data set ${ }^{12}$.

To capture the spirit of the New Keynesian models as log-linearizations, the data are transformed so that the variables are expressed in deviations

\footnotetext{
${ }^{11}$ Galí, Gertler and López-Salido (2001) specify $\widehat{s}_{i, t}$ in terms of average real marginal cost $(m c)$. Note that, in levels:

$$
s_{t}=\frac{(1-\alpha)}{m c_{t}}
$$

${ }^{12}$ The estimation was carried out using RATS, version 5 .
} 
from the "steady state"13. Both real and nominal variables are de-trended using the Hodrick-Prescott filter with smoothing parameter set to 1600 . Note that as the inflation rate and interest rate always enter the model together, all the equations are 'balanced' in terms of the levels of integration of the dependent and explanatory variables. ${ }^{14}$

\subsection{Estimation Methods}

The IS and NKPC curves is are non-linear in the structural parameters to be estimated. We use the generalized methods of moments (GMM) framework to estimate the model. Following Hansen (1982), the assumption of rational expectations suggests some natural orthogonality restrictions that can be employed as part of the estimation. Each equation estimated using GMM is of the form:

$$
\mathbf{y}_{i t}=\mathbf{f}_{i}\left(\boldsymbol{\theta}_{i}, \mathbf{z}_{i t}\right)+\mathbf{u}_{i t}
$$

where for each equation i, $\mathbf{y}_{i t}$ is the vector of dependent variables, $\boldsymbol{\theta}_{i}$ is the $\left(a_{i} \times 1\right)$ vector of unknown parameters to be estimated, and $\mathbf{z}_{i t}$ is the $\left(k_{i} \times 1\right)$ vector of explanatory variables. The GMM approach is based on the fact that $\widetilde{\boldsymbol{\theta}}_{i}$, the true value of $\boldsymbol{\theta}_{i}$, has the property $E\left[\mathbf{h}_{i}\left(\widetilde{\boldsymbol{\theta}}_{i}, \mathbf{w}_{i t}\right)\right]=0$, where $\mathbf{w}_{i t} \equiv\left(\mathbf{y}_{i t}^{\prime}, \mathbf{z}_{i t}^{\prime}, \mathbf{x}_{i t}^{\prime}\right)$, and $\mathbf{x}_{i t}$ is an $\left(r_{i} \times 1\right)$ vector of instruments that are correlated with $\mathbf{z}_{i t}$. GMM then chooses the estimate $\boldsymbol{\theta}_{i}$ so as to make the sample moment as close as possible to the population moment of zero. The validity of these instruments can be tested for each equation by using Hansen's J-test, which is distributed as a $\chi^{2}\left(r_{i}-a_{i}\right)$ statistic under the null of valid orthogonality conditions.

GMM or IV estimation has been used by a number of authors to estimate New Keynesian models of this type ${ }^{15}$. One problem is that the estimated IS and NKPC equations are highly nonlinear in parameters, and the rank condition for identification is not met unless a number of parameters in these two equations are fixed. To begin with, in estimating the output equation

\footnotetext{
${ }^{13}$ Which is commonplace in this literature (see Smets and Wouters, 2002, Leith and Malley, 2002).

${ }^{14}$ The government spending data $(G)$ is total government spending excluding transfers and interest payments, whilst we use employers' social security contributions as payroll taxes $\left(T^{P R}\right)$, and personal taxes as $(T)$.

${ }^{15}$ For instance, Galì, Gertler and Lopez-Salido (2001), Leith and Malley (2002), Kara and Nelson (2002), Muscatelli et al. (2003a,b).
} 


\begin{tabular}{cccccccc}
\hline \hline$\frac{C}{Y}$ & $\frac{G}{Y}$ & $\frac{\overline{N\left(\frac{W}{P}\right)}}{\bar{Y}}$ & $\frac{\overline{T^{P R}}}{\overline{N\left(\frac{W}{P}\right)}}$ & $\frac{\bar{T}}{\bar{Y}}$ & $\frac{\overline{T^{P R}}}{\bar{N}\left(\frac{\bar{W}}{\bar{P}}+\frac{\overline{T^{P R}}}{\bar{N}}\right)}$ & $\frac{\left(\overline{\frac{W}{P}}+\frac{\overline{T^{P R}}}{\bar{N}}\right)}{\left(\frac{W}{\bar{P}}\right)}$ \\
0.84 & 0.16 & 0.503 & 0.353 & 0.121 & 0.260 & 1.353 \\
\hline \hline
\end{tabular}

Table 1: Steady State Values

we impose that the steady-state ratios are given by their average values computed over the sub-sample period 1990(1)-1998(2) ${ }^{16}$. These values are reported in Table 1.

Furthermore, in order to increase the accuracy of the estimation we calibrate some structural parameters at values taken from other empirical studies (see Muscatelli et al. 2003b). We impose the habit formation parameter on aggregate consumption to be equal to unity $(\lambda=1)$, the coefficient of relative risk aversion $(\rho)$ to be equal to 2 , and the elasticity of demand for consumption goods $(\theta)$ as equal to 4 .

\subsection{Calibrated and Estimated Parameters}

Table 2 reports the estimated structural parameters of the Euro-area IS curve obtained using GMM over the full sample period, and the Euro-area NKPC parameters reported in Galí et al. (2001, 2003). Standard errors for all the parameters estimates are reported in brackets. Our vector of instruments $\mathbf{x}_{i t}$ include: a constant, output, government spending excluding government transfers, direct tax per worker, the nominal exchange rate, wage rate, inflation rate and the nominal interest rate. The overall fit for the estimated equation is good: the $R^{2}$ statistic for the fitted IS curve is 0.83 . The Hansen statistic for overidentifying restrictionts test is 59.39 , which is distributed as a $\chi^{2}(41)$ under the null hypothesis of valid instruments. The null hypothesis of valid instruments is not rejected at the $5 \%$ significance level. Further details on the estimation procedure are reported in Muscatelli et al. (2004).

Our point estimates thus suggest that about $50 \%$ of consumers are ruleof-thumb consumers, whilst $65 \%$ of total consumption in steady state is given by optimising consumers. Rule-of-thumb consumers account for about $61 \%$

\footnotetext{
${ }^{16}$ Our choice is motivated by the fact that observed sample ratios exhibit a trend until the end of the $80 \mathrm{~s}$ and remain stationary thereafter.
} 


\begin{tabular}{c|cccccccc}
\hline \hline Parameter & $\lambda$ & $\rho$ & $\vartheta$ & $\frac{\overline{N^{R T}}}{\bar{N}}$ & $\frac{\overline{C^{o}}}{\bar{C}}$ & $\beta$ & $\xi$ & $\gamma$ \\
Estimates & $\begin{array}{c}1.00 \\
(-)\end{array}$ & $\begin{array}{c}2.00 \\
(-)\end{array}$ & $\begin{array}{c}0.505 \\
(0.036)\end{array}$ & $\begin{array}{c}0.617 \\
(0.310)\end{array}$ & $\begin{array}{c}0.658 \\
(0.156)\end{array}$ & $\begin{array}{c}0.923 \\
(0.071)\end{array}$ & $\begin{array}{c}0.843 \\
(0.066)\end{array}$ & $\begin{array}{c}0.307 \\
(0.128)\end{array}$ \\
\hline \hline
\end{tabular}

Standard errors are reported in brackets.

Table 2: Structural parameters estimates

of total employment. Point estimates of the Calvo parameter suggests that about $84 \%$ of firms do not adjust their prices every period and of those who adjust prices, about $30 \%$ simply index prices.

In addition to the estimated parameters we set $\chi$ the proportion of homeproduced goods in the consumption of each country equal to 0.7 , which reflects a bias towards home-produced goods in most large Euroland countries. In order to close the model we need to dsecribe the behaviour of the monetary and fiscal authorities. As noted above, we do not consider strategic interactions between the ECB and the two countries' fiscal authorities. Instead we examine teh interaction between a central bank which operates a forward-looking inflation targeting framework, and fiscal authorities which rely on fiscal rules based on automatic stabilisers.

In this model, monetary policy has a relatively weak effect due to the relatively large proportion of RT consumers, who only indirectly react to the interest rate rule ${ }^{17}$. In addition, fiscal policy operates through a wider number of channels: taxation effects on consumption through liquidity constrained consumers, taxation wedge effects on inflation, and interaction effects due to the presence of RT consumers.

\subsubsection{Monetary Rule}

In contrast to the numerous papers on the behaviour of the Federal Reserve and other central banks, the empirical literature on the behaviour of the ECB is limited, mainly due to its short history. We assume that the ECB's monetary policy rule for the nominal interest rate $\widehat{i}_{t}$ follows a form similar to the standard forward-looking Taylor rule specification which has become

\footnotetext{
${ }^{17}$ As shown in Galì et al. (2002), rule-of-thumb consumers are affected by interest rate changes only to the extent that the real wage adjusts following the new labour conditions determined by the optimising consumers' reaction to such interest rate changes
} 
commonplace in the literature $^{18}$ (see Clarida, Galí and Gertler, 1998, 2000; Muscatelli et al. 2002; Giannoni and Woodford, 2002a,b):

$$
\widehat{i_{t}}=\phi_{1} E_{t} \widehat{\pi}_{t+q}+\phi_{2} \widehat{y}_{t+s}+\phi_{3} \widehat{i}_{t-1}
$$

where we also allow for inertia in the rule, due to interest-rate smoothing if $\phi_{3} \neq 0$.

As shown by Sauer and Sturm (2003) this forward-looking inertial Taylor rule fits the Euroland data reasonably well for teh post-EMU period. We use their estimates of the $\phi_{i}$ parameters to simulate our model. This provides us with a benchmark against which to assess the performance of different designs for automatic fiscal stabilizers in our structural model.

\subsubsection{Fiscal Rules}

Unlike Muscatelli et al. (2003a), we consider simple format for our fiscal policy rules and let automatic stabilizers to depend on current real activity condition and lagged debt accumulation (relative to output). Thus:

$$
\begin{aligned}
\widehat{g}_{t} & =-\delta_{1} \widehat{y}_{t}-\delta_{2}\left(\widehat{b}_{t-1}-\widehat{y}_{t-1}\right) \\
\widehat{g}_{t}^{*} & =-\delta_{1} \widehat{y}_{t}^{*}-\delta_{2}\left(\widehat{b}_{t-1}^{*}-\widehat{y}_{t-1}^{*}\right) \\
\widehat{\tau}_{t} & =\varphi_{1} \widehat{y}_{t}+\varphi_{2}\left(\widehat{b}_{t-1}-\widehat{y}_{t-1}\right) \\
\widehat{\tau}_{t}^{*} & =\varphi_{1} \widehat{y}_{t}^{*}+\varphi_{2}\left(\widehat{b}_{t-1}^{*}-\widehat{y}_{t-1}^{*}\right)
\end{aligned}
$$

where $\widehat{\tau}_{t}$ is the vector of our two tax measures, personal taxes $\widehat{t}_{t}$ and payroll taxes, $\widehat{t}_{t}^{T R}$. Our taxation rule therefore imposes the same adjustment pattern on both taxes, and does not look at how a mix of tax measures might improve the design of policy ${ }^{19}$. The importance of the fiscal policy mix is considered

\footnotetext{
${ }^{18}$ The main difference is that we use a contemporaneous value of the output gap (see Muscatelli et al. 2002) as opposed to expected future values, as in Clarida, Gali and Gertler (1998, 2000). For a detailed discussion of these issues, see Giannoni and Woodford $(2002 \mathrm{a}, \mathrm{b})$. For an alternative approach to modeling interest rate responses, involving nonlinearities in reaction functions, see Cukierman and Muscatelli (2001).

${ }^{19}$ Andres and Domenech (2003) provide an analysis of how different tax measures might impact on output and inflation variability.
} 
further below. As discussed above, we have a limited feedback to the debt accumulation, through a debt to GDP term which approximates to a response to the debt to GDP ratio.

For our baseline case, we set $\delta_{1}=\varphi_{1}=0.5$ and $\delta_{2}=\varphi_{2}=0.05$. A coefficient of 0.5 on output is consistent with the empirical evidence in Van Den Noord (2000) and adopted in studies on fiscal stabilization (e.g. Westaway, 2003). The coefficient on debt ensures stability but ensures that this does not swamp the impact of fiscal stabilisers given the configuration of the temporary shocks.

\subsection{Dynamic Simulations}

Having obtained the structural parameter estimates, we can perform dynamic simulations of our two-country New Keynesian model ${ }^{20}$ and examine the transmission mechanism of fiscal and monetary policies.

We focus on the dynamic model solution under rational expectations. To illustrate the properties of the model, we shocking each structural equation and policy equation in turn, and examine the impulse responses. As we do not have an estimated wage equation, we assume a minimum amount of nominal inertia in the model, by stipulating that nominal wages adjust gradually towards the initial real wage equilibrium with an autoregressive parameter of 0.5 per quarter. Employment is determined by the log-linearization of the production technology (12).

$(* * *$ insert figures 1 to 4 here $* * *)$

\section{Designing Fiscal Policy in a Monetary Union}

We now examine the extent to which national fiscal policies can assist with macroeconomic adjustment in EMU. The key issues we consider are: do automatic stabilisers actually assist the ECB's function of stabilising output and inflation in the union, and in the individual countries, i.e. do the fiscal authorities assist or impede the efforts of the ECB? Which fiscal instruments

\footnotetext{
${ }^{20}$ The model is solved using Winsolve version 3.0 (see Pierse, 2000), which provides numerical solutions for linear and non-linear rational expectations models. We solve our model using the Stacked Newton method in Winsolve. In solving the models with structural shocks (and further below with policy shocks) these are treated as unanticipated by economic agents.
} 
are more effective in stabilising the union and the individual economies? How do the stabilisation properties of fiscal policy vary in response to symmetric and asymmetric shocks?

\subsection{What is the Value Added from Fiscal Stabilisers in Individual Countries?}

We now simulate the model in response to a temporary demand (IS) and a temporary supply (NKPC) shock to one of the two countries $(\mathrm{H})$. We consider a shock of $1 \%$ in the first period which then decays over time with an autoregressive parameter of 0.5. The reason for not considering pure asymmetric shocks (shocks of equal and opposite sign on each EMU country) is that, given the identical structure of the two countries, and that the ECB is assumed to target EMU average outcomes, monetary policy will not react to such shocks initially. Following the asymmetric demand and supply shocks considered here, the union's inflation and output levels will change, thus triggering a response from the ECB.

We do not conduct a formal welfare analysis of the policy regimes considered, as this is complicated by the presence of heterogeneous consumers (optimisers and RT consumers) ${ }^{21}$. Instead our focus is on output and inflation variability, which allows us to gauge how fiscal policy design can impact on output and inflation variability.

In the case of each shock, we consider the following four policy scenarios:

1. where the ECB operates its policy rule (24), but where fiscal policy is kept exogenously fixed, i.e. the automatic stabilizers (25) and (27) are kept switched off;

2. where only the government spending rule is switched on (25) together with the monetary policy rule;

3. where only the taxation rules are switched on (27) together with the monetary policy rule;

4. where both fiscal rules are switched on, (25) and (27), together with the monetary policy rule .

\footnotetext{
${ }^{21}$ See for instance Benigno and Woodford (2003). We are currently considering the extension of our modeling framework to include some welfare analysis.
} 
This will allow us to compute the value added in terms of the impact on output and inflation variability. We report the results in Tables 3 and 4 for both asymmetric demand and supply shocks (modelled respectively as a transitory shock to the IS curve in country $\mathrm{H}$ and the Phillips Curve in country $\mathrm{H}$ ), and symmetric demand and supply shocks (transitory shocks to IS curves in both countries and Phillips Curves in both countries respectively). The results in Tables 3 and 4 are reported as the ratio of the variances of output (for each country and for the output differential) and inflation (for both product prices $\pi$ and consumer prices $\pi^{c}$ ) and in the scenarios 2-4 relative to scenario 1. Thus, for instance $\frac{G}{M}$ gives the relative variance of output and inflation under policy scenario 2 relative to 1 , and $\frac{T+G}{M}$ reports the relative variances for scenario 4 relative to 1 . A value of the variance ratio in excess of unity suggests that adding the fiscal instrument(s) is destabilising relative to using ECB policy alone, and a value of the ratio less than unity suggest that the fiscal policy instrument(s) in question reduce the variability of output or inflation. In the case of the symmetric shocks the variability of output and inflation is obviously identical across countries because of the symmetry of the model.

Turning first to Table 3, we immediately see that both fiscal instruments stabilise output and their role is enanched when activeted simultaneously. The latter result is particularly true in the case of asymmetric demand shock where the variability of domestic output is reduced by approximately $80 \%$. To a much lesser extent this conclusion also holds for asymmertic supply shocks.

Turning next to Table 4, the results for symmetric shocks also suggest a complementarity between the two fiscal policy instruments. This is in sharp contrast with the "Brussels consensus" based on the view that the ECB alone should stabilize the union-wide economy (Buti et al., 2001). ${ }^{22}$

\footnotetext{
${ }^{22}$ Following Van Den Noord (2000), Westaway (2003) and Andres and Domenech (2003), in our simulation exercises we also experimented backward-looking specification, where fiscal instruments depend on $y_{t-1}$. Our results are reboust to this modification. However, some important differences arise when the fiscal rules include an autoregressive term with coefficient 0.5 . In this case the stebilising properties of automatic stabilisers are significantly weakened.
} 
Asy. Demand Shock Asy. Supply Shock

\begin{tabular}{lcccccc}
\hline \hline & $\frac{T+G}{M}$ & $\frac{T}{M}$ & $\frac{G}{M}$ & $\frac{T+G}{M}$ & $\frac{T}{M}$ & $\frac{G}{M}$ \\
\cline { 2 - 7 } $\operatorname{VAR}(Y)$ & 0.216 & 0.960 & 0.885 & 0.834 & 0.955 & 0.868 \\
$\operatorname{VAR}\left(Y^{*}\right)$ & 0.191 & 0.913 & 0.768 & 0.809 & 0.942 & 0.845 \\
$\operatorname{VAR}\left(Y-Y^{*}\right)$ & 0.211 & 0.951 & 0.863 & 0.824 & 0.949 & 0.858 \\
& & & & & & \\
$\operatorname{VAR}(\pi)$ & 0.204 & 0.922 & 0.889 & 0.982 & 0.992 & 1.001 \\
$\operatorname{VAR}\left(\pi^{*}\right)$ & 0.181 & 0.853 & 0.426 & 1.150 & 1.217 & 0.970 \\
$\operatorname{VAR}\left(\pi^{c}\right)$ & 0.214 & 0.949 & 0.659 & 0.995 & 0.992 & 1.001 \\
$\operatorname{VAR}\left(\pi^{c *}\right)$ & 0.141 & 0.728 & 0.187 & 1.009 & 1.014 & 0.998 \\
\hline \hline
\end{tabular}

Table 3: Relative Variances to asymmetric shocks

\begin{tabular}{ccccccc} 
& \multicolumn{2}{c}{ Sym. Demand Shock } & \multicolumn{3}{c}{ Sym. Supply Shock } \\
\hline \hline $\operatorname{VAR}(Y)=\operatorname{VAR}\left(Y^{*}\right)$ & $\frac{T+G}{M}$ & $\frac{T}{M}$ & $\frac{G}{M}$ & $\frac{T+G}{M}$ & $\frac{T}{M}$ & $\frac{G}{M}$ \\
\cline { 2 - 7 } & 0.894 & 0.973 & 0.920 & 0.894 & 0.984 & 0.922 \\
$\operatorname{VAR}(\pi)=\operatorname{VAR}\left(\pi^{*}\right)$ & 1.005 & 1.058 & 0.964 & 0.999 & 0.999 & 1.000 \\
$\operatorname{Var}\left(\pi^{c}\right)=\operatorname{Var}\left(\pi^{c *}\right)$ & 1.005 & 1.058 & 0.964 & 0.999 & 0.999 & 1.000 \\
\hline \hline
\end{tabular}

Table 4: Relative Variances to symmetric shocks

\section{Conclusions}

This paper has used a two-country New Keynesian DGE model to examine the extent to which national fiscal policies can assist macroeconomic adjustment within EMU, in response to a variety of shocks. We use a model which embodies liquidity constrained (rule-of-thumb) consumers and home bias in consumption, and use some recent estimates of the structural model on Euro area data to calibrate our model.

The key conclusion which emerges from our analysis is that automatic stabilizers based on both government spending and taxation policy seem to combine efficiently with forward-looking (inertial) Taylor rules on the part of the ECB in the case of symmetric shocks. In contrast with the popular view that takes for granted the effectiveness of automatic stabilisers in the face of asymmetric shocks we find that national stabilisers play a role only if private 
consumption and/or government spending exhibit a significant home bias.

Further research should consider the possibility that progressive income tax rates could help to stabilise inflation through the well-known fiscal drag mechanism.

\section{References}

Andres, J. and R. Domenech, 2003. "Automatic Stabilisers, Fiscal Rules and Macroeconomic Stability.", mimeo., Universidad de Valencia, January.

Benigno, P. and M. Woodford, 2003. "Optimal Monetary and Fiscal Policy: a Linear-Quadratic Approach" mimeo.

Blanchard, O.J., 1985. "Debt, deficit and finite horizons." Journal of Political Economy, 93, 223-47.

Blanchard, O.J. and R. Perotti, 2002. "An empirical characterization of the dynamic effects of changes in government spending and taxes on output." Quarterly Journal of Economics, 117, 1329-68.

Bohn, H., 1988. "The Behavior of US Public Debt and Deficits." Quarterly Journal of Economics, 113, pp.949-63.

Buiter, W.H., 2001. "The fiscal theory of the price level: a critique." Economic Journal, 112, 459-80.

Buti, M., Roeger W. and in't Veld 2001. "Stabilizing Output and Inflation in EMU: Policy Conflicts and Cooperation under the Stability Pact". Journal of Common Market Studies, forthcoming.

Campbell, J.Y. and J.H. Cochrane, 1999. "By Force of Habit: A Consumptionbased Explanation of Aggregate Stock Market Behavior." Journal of Political Economy, 107, 2, pp.205-51.

Canzoneri, M.B., R.E. Cumby and B.T. Diba, 2001. "Is the price level determined by the needs for fiscal solvency?" American Economic Review, 91, 1221-38.

Carroll, C.D., 2000, "Solving Consumption Models with Multiplicative Habits." Economics Letters, 68, pp.67-77.

Christiano, L.J., M. Eichenbaum, and C. Evans, 2001. "Nominal Rigidities and the Dynamic Effects of a Shock to Monetary Policy". NBER Working Paper \#8403.

Clarida, R., J. Galí, and M. Gertler, 1998. "Monetary policy rules in practice: some international evidence". European Economic Review, vol. 42, no. 6, pp. 1033-1067. 
Clarida, R., J. Galí, and M. Gertler, 2000. "Monetary Policy Rules and Macroeconomic Stability: Evidence and Some Theory". Quarterly Journal of Economics, vol. CXV, issue 1, 147-180.

Cukierman, A., and V. Anton Muscatelli, 2001. "Do Central Banks have Precautionary Demands for Expansions and for Price Stability? - Theory and Evidence". CESifo Discussion Paper n.764.

Erceg, C.J., D.W. Henderson, and A.T. Levin, 2000. "Optimal Monetary Policy with Staggered Wage and Price Contracts". Journal of Monetary Economics, 46, 281-313.

Fagan, G., J. Henry, R. Mestre, 2001. "An area-wide model (AWM) for the Euro area." ECB Working Paper Series No. 42, January.

Fatás, A. and I. Mihov, 2001. "Government size and automatic stabilizers: international and intranational evidence." Journal of International Economics, 55, 3-28.

Favero, C.A. and T. Monacelli, 2003. "Monetary-Fiscal Mix and Inflation Performance: Evidence from the US." CEPR Discussion Paper n.3887, May.

Galí, J., 2003 "New Perspectives on Monetary Policy, Inflation, and the Business Cycle" in Advances in Economic Theory, edited by: M. Dewatripont, L. Hansen, and S. Turnovsky, vol. III, 151-197, Cambridge University Press 2003.

Galí, J., and M. Gertler, 1999. "Inflation Dynamics: A Structural Econometric Analysis" Journal of Monetary Economics, vol. 44, no 2, 195-222.

Galí, J., M. Gertler and D. López-Salido, 2001. "European Inflation Dynamics". European Economic Review, vol. 45, no 7, 1237-1270.

Galí, J., M. Gertler and D. López-Salido, 2003. Erratum to "European Inflation Dynamics". European Economic Review, vol. 47, no 4, 759-760.

Galí, J., D. López-Salido, and J. Valles, 2002. "Understanding the Effects of Government Spending on Consumption." mimeo., U. Pompeu Fabra. October.

Giannoni, M.P., and M. Woodford, 2002a. "Optimal Interest-Rate Rules: I. General Theory". NBER Working Paper \#9419.

Giannoni, M.P., and M. Woodford, 2002b. "Optimal Interest-Rate Rules: I. Applications". NBER Working Paper \#9420.

Giavazzi, F., T. Jappelli, and M. Pagano, 2000. "Searching for non-linear effects of fiscal policy: evidence from industrial and developing countries." European Economic Review, 44, 1259-89.

Gordon, D.B. and E.M. Leeper, 2003. "Are Countercyclical Fiscal Policies Counterproductive?" paper presented at 5th Bundesbank Spring Conference, 
May.

Hansen, L. P., 1982, "Large Sample Properties of Generalized Method of Moments Estimators". Econometrica, 50, 1029-1054.

Jones, J.B., 2002, "Has Fiscal Policy Helped Stabilize the Postwar US Economy?" Journal of Monetary Economics, 49, 709-46.

Kara, A. and E. Nelson, 2002, "The Exchange Rate and Inflation in the UK". Bank of England, External MPC Unit, Discussion Paper n. 11.

Leith, C., and S. Wren-Lewis, 2000. "Interactions between monetary and fiscal policy rules". The Economic Journal, 110, C93-C108.

Leith, C., and J. Malley, 2002. "Estimated General Equilibrium Models for the Evaluation of Monetary Policy in the US and Europe". University of Glasgow Discussion Paper.

Linnemann, L. and A. Schabert, 2003. "Fiscal policy in the New Neoclassical Synthesis." Journal of Money Credit and Banking, 35, 911-29.

Mountford, A. and Uhlig, H., 2002, "What are the effects of fiscal policy shocks?". CEPR Discussion Paper \#3338.

Muscatelli, A., P. Tirelli and C. Trecroci, 2002. "Does institutional change really matter? Inflation targets, central bank reform and interest rate policy in the OECD countries". The Manchester School, vol. 70 (4), 2002.

Muscatelli, A., P. Tirelli and C. Trecroci, 2003a. "The Interaction of Fiscal and Monetary Policies: Some Evidence using Structural Models.", CESifo Working Paper n.1060, forthcoming, Journal of Macroeconomics.

Muscatelli, A., P. Tirelli and C. Trecroci, 2003b. "Can fiscal policy help macroeconomic stabilization? Evidence from a New Keynesian model with liquidity constraints", CESifo Working Paper, n.1171.

Muscatelli, V.A., P. Tirelli and C. Trecroci, 2004a. "Monetary and fiscal policy interactions over the cycle: some empirical evidence". In R. Beetsma, C. Favero, A. Missale, V.A. Muscatelli, P. Natale and P. Tirelli (eds.), Fiscal Policies, Monetary Policies and Labour Markets. Key Aspects of European Macroeconomic Policies after Monetary Unification. Cambridge: Cambridge University Press.

Pierse, R., 2000. Winsolve, version 3.5. University of Surrey.

Sauer, S. and J.E. Sturm, 2003. "ECB monetary policy: how well does the Taylor Rule describe it?" mimeo., University of Munich.

Sbordone, A.G., 2002. "Prices and Unit Labor Costs: A New Test of Price Stickiness". Journal of Monetary Economics, vol. 49 (2), pp. 265-292. 
Schabert, A., 2004. "Interactions of monetary and fiscal policy via open market operations." Economic Journal, 114, C186-206.

Schmitt-Grohé, S., and M. Uribe, 2001. "Optimal Fiscal and Monetary Policy Under Sticky Prices". NBER Working Paper \#9220.

Sims, C.A., 1994. "A simple model for the study of the determination of the price level and the interaction of monetary and fiscal policy.'Economic Theory, 4, 381-99.

Smets, F., and R. Wouters, 2002 "An Estimated dynamic stochastic general equilibrium model of the euro area", European Central Bank Working Paper n.171.

Taylor, J.B., 2000a. "The Policy Rule mix: a Macroeconomic Policy Evaluation". Unpublished manuscript, Stanford University.

Taylor, J.B., 2000b. "Reassessing Discretionary Fiscal Policy". Journal of Economic Perspectives, vol. 14, n.3, pp. 21-36.

von Hagen, J., Hughes Hallett, Strauch, R., 2001. "Budgetary Consolidation in EMU". Economic Papers No. 148. March 2001. European Commission. Brussels.

Westaway, P., 2003. 'Modelling Shocks and Adjustment Mechanisms in EMU'. HM Treasury, EMU Studies.

Woodford, M., 1994. "Monetary policy and price level determinacy in a cash-in-advance economy.' Economic Theory, 4, 345-80.

Woodford, M., 2002. Interest and Prices: Foundations of a Theory of Monetary Policy. Princeton University Press.

Wyplosz, C., 1999. "Economic Policy Coordination in EMU: Strategies and Institutions". ZEI Policy Paper B11. 
Output (country H)

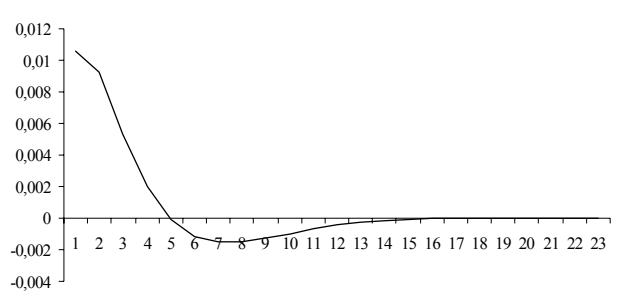

Inflation (country H)

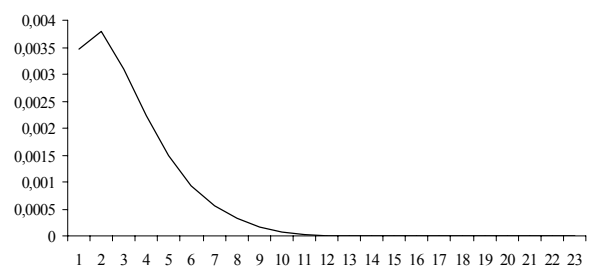

Payroll taxation (country H)

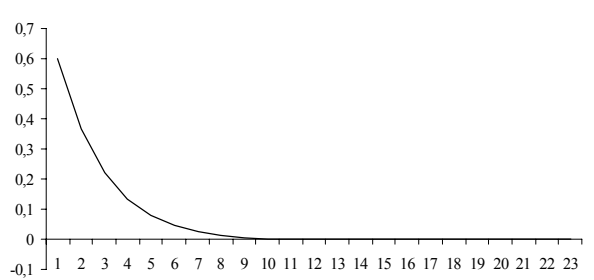

Output (country F)

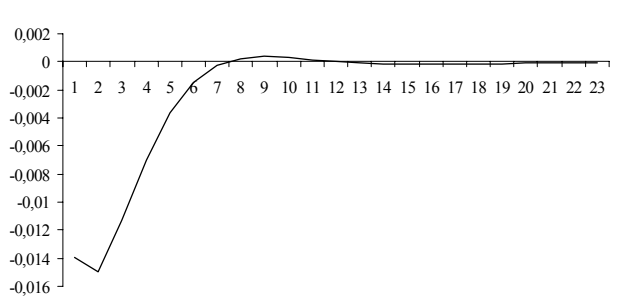

Inflation (country F)

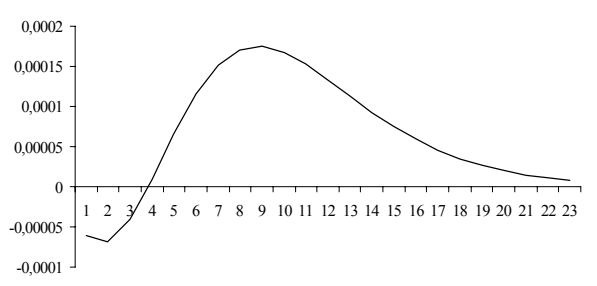

Nominal interest rate

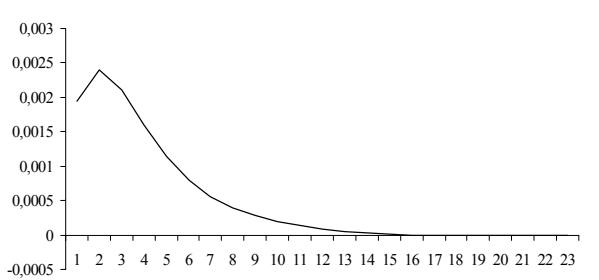

Figure 1. Impulse response functions to a $1 \%$ payroll taxation shock. 
Output (country H)

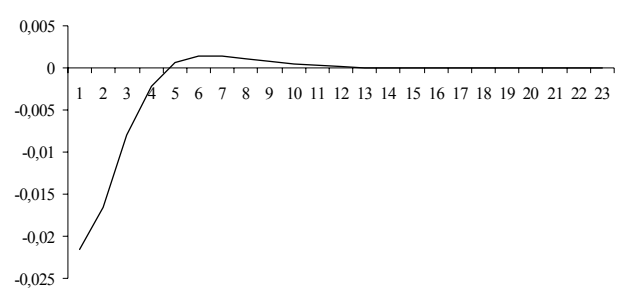

Inflation (country H)

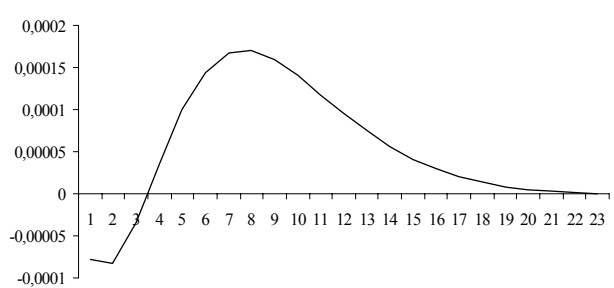

Lump-sum taxation (country H)

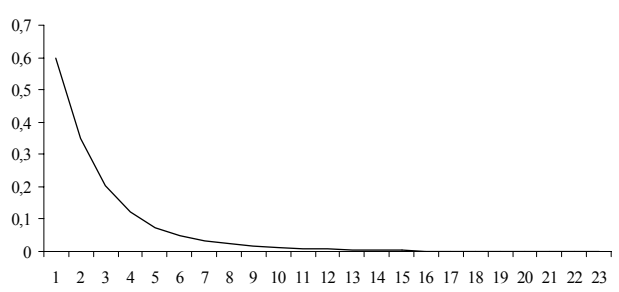

Output (country F)

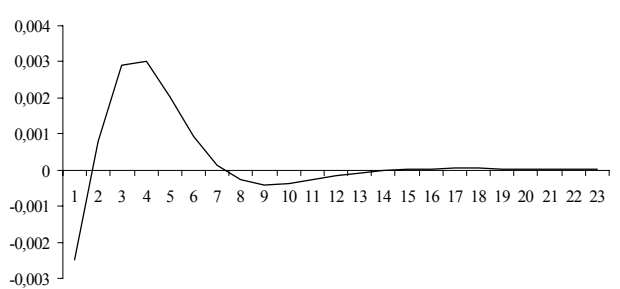

Inflation (country F)

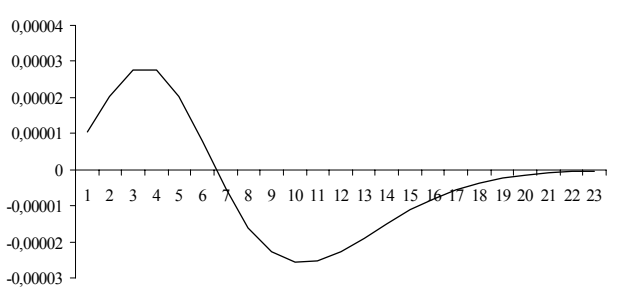

Nominal interest rate

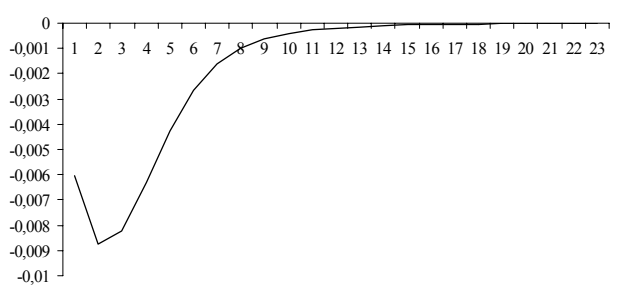

Figure 2. Impulse response functions to a $1 \%$ lump-sum taxation shock. 
Output (country H)

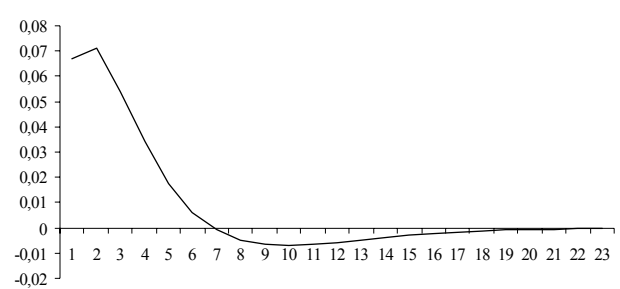

Inflation (country H)

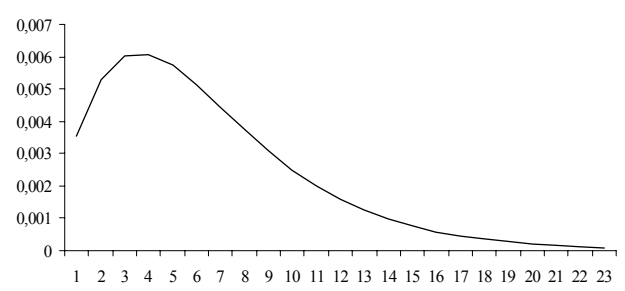

Nominal Interest rate

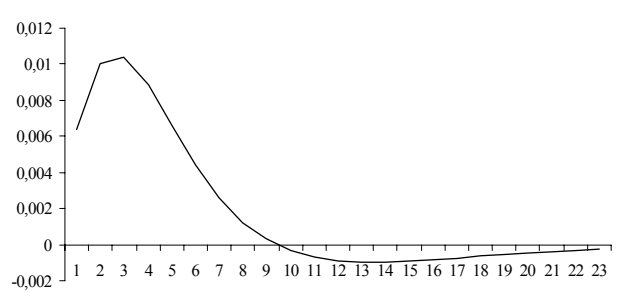

Output (country F)

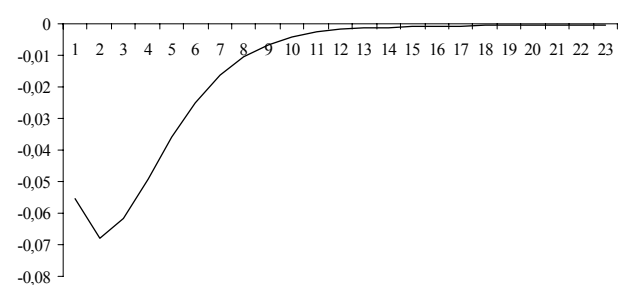

Inflation (country F)

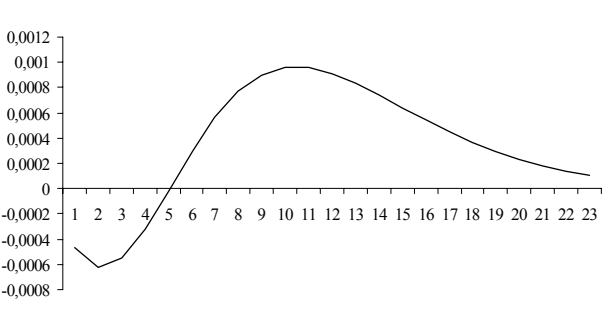

Government expenditure

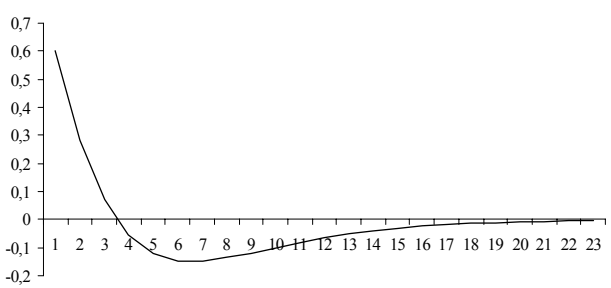

Figure 3. Impulse response functions to a $1 \%$ government expenditure shock. 
Output (country H)

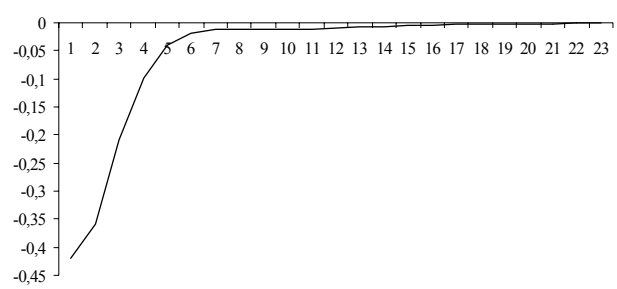

Inflation (country H)

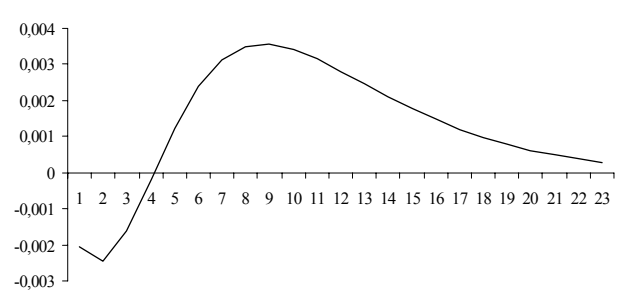

Nominal interest rate

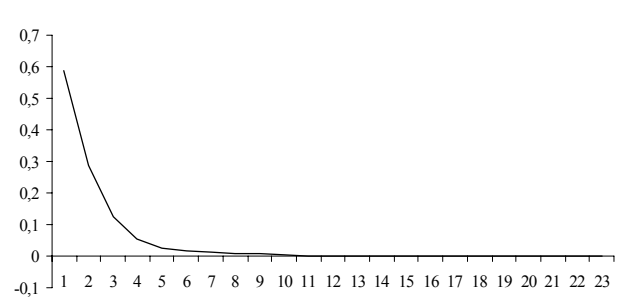

Output (country F)

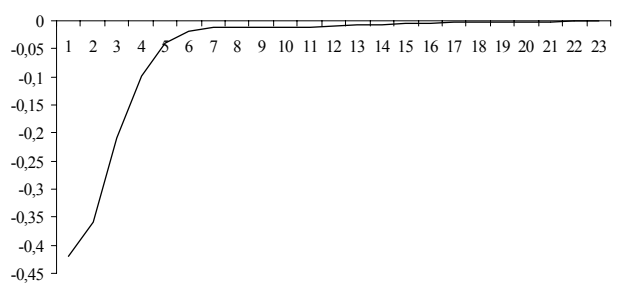

Inflation (country F)

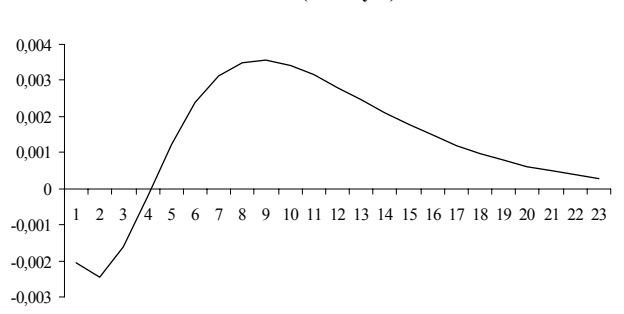

Figure 4. Impulse response functions to a $1 \%$ monetary policy shock. 